\title{
MENGGUGAT UU PENYIARAN DI INDONESIA (ANALISA FRAMING PEMBERITAAN GUGATAN RCTI DAN INEWS TV TENTANG UU 32 Tahun 2002 pada SINDONEWS \& DETIK.COM PERIODE 27 AGUSTUS - 20 SEPTEMBER 2020)
}

\author{
Fitria Safiratun Nabilah ${ }^{1}$, Jessica Wiguna ${ }^{2}$, Noerazrie Imania Putri ${ }^{3}$, Roziana Febrianita ${ }^{4}$ \\ Universitas Pembangunan Nasional "Veteran" Jawa Timur \\ fitriasnabilah@gmail.com ${ }^{1}$, mtjessica.w@gmail.com² ${ }^{2}$ noerazrieip@gmail.com³ \\ rozianafebrianita.ilkom@upnjatim.ac.id ${ }^{4}$
}

\begin{abstract}
Abstrak
Pada Juni 2020 RCTI dan iNEWS TV menggugat UU penyiaran Nomor 32 Tahun 2002 ke MK. Perihal yang digugat adalah menuntut pengajuan uji ulang materi soal UU Penyiaran dan menilai Pasal 1 angka 2 UU Penyiaran. Gugatan diajukan sebab pasal tersebut dinilai menyebabkan ketidakadilan atau perlakuan berbeda antara penyelenggara penyiaran konvensional yang menggunakan frekuensi radio dengan penyelenggara penyiaran Over The Top (OTT) yang menggunakan internet, seperti Instagram, Youtube, Netflix dan aplikasi streaming sejenisnya. Penelitian ini bertujuan untuk menganalisis bagaimana pembingkaian oleh sindonews.com dan detik.com terkait pemberitaan tersebut. Penelitian ini menggunakan metodologi kualitatif deskriptif dengan analisis framing model Zhongdan Pan dan Gerald M. Kosicki. Fokus penelitian ini adalah sintaksis, skrip, tematik, dan retoris. Data penelitian merupakan kumpulan berita dari Sindonews.com dan Detik.com periode 27 Agustus - 14 September 2020, sebab kedua media dinilai aktif mengunggah berita dengan topik tersebut. Kesimpulan penelitian menyebutkan bahwa terdapat framing yang berbeda antara kedua media. Sindonews.com memberikan dukungan pada gugatan RCTI dan iNews TV dan mendorong untuk segera dilakukannya revisi UU Penyiaran. Sementara detik.com memberikan framing melemahkan dukungan pada gugatan RCTI dan iNews TV serta tidak menstimulasi adanya urgensi revisi UU Penyiaran.
\end{abstract}

Kata Kunci: UU Penyiaran, Analisa Framing, RCTI, iNews TV

\begin{abstract}
In June 2020 RCTI and iNEWS TV sued the Broadcasting Law no. 32 of 2002 to the Court. The subject of the lawsuit is to demand the submission of a material re-test of the Broadcasting Law and assess Article 1 number 2 of the Broadcasting Law. The lawsuit was filed because the article is considered to cause injustice or different treatment between conventional broadcasters who use radio frequencies and broadcasters Over The Top (OTT) who use the internet, such as Instagram, Youtube, Netflix and similar streaming applications. This study aims to analyze how framing by Sindonews.com and Detikcom related to the news. This study used descriptive qualitative methodology with framing analysis of Zhongdan Pan and Gerald M. Kosicki models. The focus of this research is syntax, script, thematic, and rhetoric. The research data is a collection of news from Sindonews.com and Detik.com period 27 August - 14 September 2020, because both media are considered actively uploading news with the topic. The conclusion of the study states that there are different framings between the two media. Sindonews.com provide support to the lawsuit RCTI and iNews TV and pushed for immediate revision of the Broadcasting Law. Whereas detik.com provide framing weakens encouragement for RCTI and iNews TV lawsuits and does not stimulate the urgency of revision of the Broadcasting Law.
\end{abstract}

Keywords: Broadcasting Law, Framing Analysis, RCTI, iNEWS TV 


\section{PENDAHULUAN}

Buku yang ditulis oleh Romli (2012) berjudul Jurnalistik Online: Panduan Mengelola Media Online menyatakan bahwa media online merupakan salah satu dari bentuk media massa yang disajikan secara online dan berbasis internet. Pesatnya perkembangan teknologi komunikasi membuat banyak perusahaan media juga bermunculan di Indonesia. Dilansir menurut Aulia (dalam tirto.id, 2018), menyatakan Indonesia memiliki delapan raja media yang menguasai jalur media massa baik tradisional televisi dan cetak. Jumlah ini terhitung lebih banyak dibandingkan negara lainnya. Sebagai lembaga yang berwenang mengatur segala peraturan negara termasuk halnya arus informasi, pemerintah membuat peraturan atau payung hukum bagi perusahaan media serta aturan kegiatan di dalamnya, agar sesuai dengan UU yang berlaku. Hal ini dikarenakan semakin berkembangnya teknologi komunikasi dan informasi semakin heterogen jumlah media sehingga membuat tidak terkendalinya arus informasi yang masuk, sehingga berdampak pada banyak informasi yang bertentangan dengan tujuan nasional.

Dilansir dari Kompas.com pada tahun lalu masyarakat tengah dihebohkan terkait gugatan dua perusahaan media massa besar yang ada di Indonesia yakni PT Rajawali Citra Televisi Indonesia PT Visi Citra Mitra Mulia yang selanjutnya dalam penelitian ini akan disingkat RCTI dan iNEWS TV. RCTI dan iNEWS TV menggugat Undang-Undang Nomor 32 Tahun 2002 tentang Penyiaran (UU Penyiaran) ke Mahkamah Konstitusi (MK). Mereka menuntut pengajuan uji ulang materi soal UU Penyiaran dan menilai Pasal 1 angka 2 UU Penyiaran menyebabkan ketidakadilan atau perlakuan berbeda antara penyelenggara penyiaran konvensional yang menggunakan frekuensi radio dengan penyelenggara penyiaran Over The Top (OTT) yang menggunakan internet, seperti Instagram, Youtube, Netflix dan aplikasi streaming sejenisnya.

Sebelumnya pemerintah telah mengatur regulasi tentang media dan kegiatannya dalam berbagai bentuk undang - undang yang diantaranya UU Pers, UU Penyiaran dan UU ITE. Gugatan RCTI dan iNEWS TV secara kronologis diawali dengan pengajuan materi perihal UU Nomor 32 Tahun 2002 Pasal 1 Angka 2 pada Juni lalu. Dalam gugatan RCTI dan iNEWS TV, penggugat mempertanyakan pasal 1 angka 1 UU Penyiaran yang berbunyi : "Siaran ialah pesan atau rangkaian pesan dalam bentuk audio, visual, atau audio visual atau yang berbentuk grafis, karakter, baik yang bersifat interaktif atau pun tidak, yang dapat diterima melalui perangkat penerima siaran”. Mereka juga menilai Pasal 1 Angka 2 UU Penyiaran bersifat ambigu dan menciptakan ketidakpastian hukum.

Dalam Pasal 1 Angka 2 UU Penyiaran disebutkan bahwa "Penyiaran merupakan sebuah kegiatan pemancarluasan siaran melalui sarana pemancaran dan sarana transmisi di darat, laut, udara ataupun antariksa dengan menggunakan spektrum frekuensi radio melalui udara, kabel, dan media lainnya untuk dapat diterima secara serentak dan bersamaan oleh masyarakat dengan perangkat penerima siaran; dan kegiatan menyebarluaskan atau mengalirkan siaran dengan menggunakan internet untuk dapat diterima oleh masyarakat sesuai dengan permintaan dan kebutuhan dengan perangkat penerima siaran". RCTI dan iNEWS TV merasa dirugikan serta adanya diskriminasi di berbagai hal. Contohnya, ketika melakukan kegiatan penyiaran, Penyiaran konvensional dalam hal ini RCTI dan iNEWS TV terlebih dahulu harus berbadan hukum, hingga memperoleh izin siaran. Berbeda dengan penyelenggara siaran berbasis internet (OTT) tidak perlu memenuhi persyaratan diatas. 
Penyiaran konvensional berpedoman perilaku penyiaran dan standar program penyiaran (P3SPS). Bila terjadi pelanggaran, penyelenggara terancam mendapatkan sanksi yang diberikan oleh KPI. Namun, tidak berlaku bagi penyedia layanan berbasis OTT.

Gugatan yang diajukan oleh RCTI dan iNEWS TV ini menuai pro dan kontra di dalam masyarakat, Ada pihak yang mendukung dan tidak mendukung atau bahkan netral terkait peristiwa ini. Sama halnya dengan pemberitaan di media terkait peristiwa ini yang cukup beragam ada pro dan kontra tergantung bagaimana cara media memberitakan kasus tersebut. Berdasarkan alasan tersebut peneliti ingin menganalisis dan mencari tahu terkait sudut pandang media massa terhadap peristiwa tersebut dengan menggunakan analisis framing.

Berbicara mengenai framing, G.J. Aditjondro mengartikan framing sebagai sebuah metode yang menyajikan realitas dimana kebenaran tentang suatu peristiwa tidak diingkari secara total, melainkan dibelokkan secara halus, dengan memberikan sorotan terhadap aspekaspek tertentu saja, diperkuat dengan menggunakan istilah yang memiliki makna atau konotasi tertentu dan dengan bantuan seperangkat foto, karikatur, dan alat ilustrasi lainnya. Perangkat kognisi yang analisis framing dipakai untuk membedah cara-cara atau ideologi media saat mengkonstruksikan fakta (Sobur, 2012). Adapun Zhongdan Pan dan Kosaci (Dalam Eriyanto, 2011) mendefinisikan framing yakni strategi konstruksi dan proses dari sebuah berita. Framing adalah seperangkat kognisi yang digunakan dalam mengkode informasi, menafsirkan peristiwa, dan kemudian dihubungkan dengan rutinitas dan konvensi pembentukan pemberitaan.

Berita adalah salah satu karya jurnalistik online yang ditulis berdasarkan fakta atau data peristiwa. Jurnalistik online dicirikan sebagai praktik jurnalist yang mempertimbangkan berbagai format bentuk media (multimedia) untuk menyusun isi liputan dan memungkinkan terjadinya interaksi antara jurnalis dengan audiens serta dapat menghubungkan berbagai elemen berita dengan sumber-sumber online sejenisnya (Romli, 2012: 14). Produk berita yang dihasilkan oleh media massa konvensional tidak berbeda jauh dengan berita yang dihasilkan portal berita online pada umumnya, yakni seputar foto atau video jurnalis, artikel, berita dan lainnya.

Leornada dalam penelitiannya menyatakan bahwa analisis framing masuk dalam pandangan konstruktivis, dimana setiap teks berita yang sampai ke pembaca telah dikonstruksikan terlebih dahulu oleh media massa (Leonarda, 2013). Pandangan ini menilai bahwa berita yang sampai ke pembaca adalah berita yang subjektif, bukan objektif. Berita yang dihadirkan oleh pers tidak hanya menyajikan sebuah realitas saja, melainkan terdapat pandangan yang dikonstruksikan dalam mengemas berita. Selaras dengan hal tersebut menurut Sudibyo dalam (Sari, 2018), media massa tidak sepenuhnya netral. Dalam memberitakan sebuah berita, mereka berpihak. Hal ini berarti portal berita online memiliki keberpihakan tergantung kepentingan media itu sendiri.

Bungin (2011), seorang pengemuka teori konstruksi sosial media massa, mengemukakan bahwa media massa memiliki pengaruh yang besar dalam mengkonstruksi 
sosial atau realita. Media massa dianggap sangat substantif dalam proses eksternalisasi, subjektivitas, dan internalisasi. Karena jangkauan media yang luas substantif yang dibangun oleh media massa memiliki sirkulasi informasi yang cepat dan meluas sehingga konstruksi sosial yang telah dibentuk dapat disebarkan secara langsung dan merata.

Hal ini berkaitan dengan sudut pandang media atau pembingkaian media dalam menyampaikan sebuah peristiwa yang dikemas dalam bahasa jurnalistik. Untuk mengulas dan menganalisis pembingkaian yang dilakukan oleh media massa salah satunya dapat menggunakan analisis framing. Berbincang mengenai analisis framing, metode dan teori ini sudah banyak digunakan oleh penelitian terdahulu sebagai metode penelitian dalam menganalisis fenomena komunikasi.

Febrianita R (2021) dalam jurnalnya yang berjudul "Membingkai Risma di Portal Berita Online: Jejak Penanganan Covid-19 di Surabaya". Penelitian ini menggunakan analisis framing dengan model milik Robert N. Entman. Hasilnya terdapat pembingkaian yang berbeda yang disajikan oleh kedua portal berita tersebut. Adapun Detik.com membingkai dengan natural dan tidak memihak siapapun. Kemudian Kompas.com sangat berhati-hati dalam menentukan narasumber yang digunakan untuk memperkuat informasi yang diberitakannya.

Leonarda Johannes (2013) dalam penelitiannya "Analisis Framing Pemberitaan Konflik Partai Nasional Demokrat (Nasdem) Di Harian Media Indonesia Dan Koran Sindo". Pada penelitian ini menggunakan analisis framing dengan model milik Zhongdang Pan dan Gerald M. Kosicki yang melihat sudut pandang media Harian Media Indonesia dan Koran Sindo dari struktur sintaksis, skrip, retoris, dan tematik terhadap topik tersebut. Hasil penelitian ditemukan bahwa Harian Media Indonesia dan Koran Sindo membingkai berita dengan topik konflik Partai NasDem dengan mengedepankan unsur ketokohan (who), ini menunjukan terdapat unsur campur tangan kepemilikan dan keberpihakan yang terjadi pada kedua media tersebut yakni Harian Media Indonesia dan Koran Sindo yang dimiliki oleh Surya Paloh dan Hary Tanoesoedibjo.

Dari penelitian terdahulu di atas, keduanya memiliki kesamaan dengan penelitian yang dilakukan saat ini, yaitu menggunakan penelitian kualitatif dengan metode analisis framing media. Selain itu belum ada yang melakukan penelitian terhadap topik gugatan RCTI dan iNEWS TV terhadap UU Penyiaran. Pada penelitian sebelumnya juga belum ada yang mengambil sudut pandang dari dua media antara Sindonews.com dan Detik.com. Sindonews.com dan Detik.com dalam situs Alexa.com, per maret 2021, termasuk kedalam 10 besar daftar top sites yang paling sering dikunjungi dan dicari di Indonesia. Selain itu, pemilihan media didasarkan dengan alasan bahwa Sindonews.com berada di bawah payung perusahaan yang sama dengan RCTI dan iNEWS TV sedangkan Detik.com tidak memiliki hubungan dengan RCTI dan iNEWS TV.

Peneliti memilih periode 27 Agustus sampai 14 September 2020 dikarenakan, kedua media cukup sering memberitakan hal tersebut, terhitung Sindonews.com 18 berita dan Detik.com 38 berita. Berkaitan dengan hal tersebut peneliti mengambil topik tersebut yang 
diberitakan oleh Sindonews.com dan Detik.com sebagai objek penelitian. Disini peneliti menggunakan analisis framing dengan model Zhongdang Pan dan Gerald M. Kosicki yang meneliti teks berita menggunakan struktur sintaksis, skrip, retoris, dan tematik yang berfokus pada perbedaan pembingkaian beritakan oleh yang diberitakan oleh Sindonews.com dan Detik.com terkait gugatan RCTI dan iNEWS TV terhadap UU Penyiaran.

\section{METODE PENELITIAN}

Penulisan penelitian ini menggunakan jenis penelitian kualitatif. Penggunaan metode kualitatif dapat digunakan untuk menggambarkan, meringkaskan berbagai kondisi, situasi, atau fenomena realitas sosial yang ada di lingkungan masyarakat yang ini dapat menjadi objek penelitian dan berupaya menarik realitas itu ke permukaan sebagai suatu ciri, karakter, sifat, model, tanda atau gambaran tentang kondisi, situasi maupun fenomena tertentu (Bungin, 2010).

Penelitian menggunakan analisis framing model Zhongdang Pan dan Gerald M. Kosicki untuk melihat bagaimana konstruksi berita dari media online Sindonews.com dan Detik.com dalam membingkai pemberitaan tentang gugatan RCTI dan iNEWS TV terhadap UU Penyiaran serta peneliti juga ingin melihat bagaimana makna dalam teks kemudian akan mencoba menarik kesimpulan tentang konflik tersebut.

Model framing ini menjelaskan bahwa setiap berita mempunyai frame yang berfungsi sebagai pusat dari organisasi ide. Frame berhubungan dengan makna, yang artinya bagaimana seseorang memaknai suatu peristiwa dapat dilihat dari perangkat tanda yang dimunculkan dalam teks. Dalam pendekatan ini perangkat framing dibagi menjadi 4 struktur besar yakni struktur sintaksis, struktur skrip, struktur tematik, dan struktur retoris.

\section{Framing model Zhongdang Pan dan Gerald M. Kosicki}

Zhongdang Pan dan Gerald M. Kosicki (dalam Eriyanto, 2011) mengatakan bahwa wacana media merupakan proses kesadaran sosial yang melibatkan tiga elemen, yaitu sumber berita, jurnalis, dan komunikan atau audiens dalam memahami suatu budaya dan menyangkut dasar-dasar kehidupan bersosial. Model ini menjelaskan bahwa setiap berita mempunyai frame yang berfungsi sebagai pusat dari organisasi ide.

Frame berhubungan dengan makna, yang artinya bagaimana seseorang memaknai suatu peristiwa dapat dilihat dari perangkat tanda yang dimunculkan dalam teks. Handoko (2020) dalam penelitiannya menyatakan model framing dari Zhongdang Pan dan Gerald M. Kosicki merupakan model yang paling tajam. Model ini juga sangat cocok untuk menganalisa pesan dari media tertentu dalam membangun konstruksi realitas serta pembingkaian sebuah berita. Dalam pendekatan ini perangkat framing dibagi menjadi 4 struktur besar. 


\begin{tabular}{|c|c|c|}
\hline Struktur & Perangkat Framing & Unit yang diamati \\
\hline $\begin{array}{l}\text { Sintakis } \\
\text { Cara wartawan } \\
\text { menyusun fakta }\end{array}$ & 1. Skema berita & $\begin{array}{l}\text { Headline, lead, latar informasi, } \\
\text { kutipan sumber, pernyataan, penutup }\end{array}$ \\
\hline $\begin{array}{l}\text { Skrip } \\
\text { Cara wartawan } \\
\text { mengisahkan fakta }\end{array}$ & 1. Kelengkapan berita & $5 \mathrm{~W}+1 \mathrm{H}$ \\
\hline $\begin{array}{l}\text { Tematik } \\
\text { Cara wartawan menulis } \\
\text { fakta }\end{array}$ & $\begin{array}{ll}\text { 1. } & \text { Koherasi } \\
\text { 2. } & \text { Bentuk kalimat } \\
\text { 3. } & \text { Kata ganti }\end{array}$ & $\begin{array}{l}\text { Paragraf, } \\
\text { kalimat, hubungan antar kalimat }\end{array}$ \\
\hline $\begin{array}{l}\text { Retoris } \\
\text { Cara wartawan } \\
\text { menekankan fakta }\end{array}$ & $\begin{array}{ll}\text { 1. } & \text { Leksikon } \\
\text { 2. } & \text { Grafis } \\
\text { 3. } & \text { Metafora }\end{array}$ & Kata, gambar / foto, grafik \\
\hline
\end{tabular}

Tabel 1. Struktur Framing Zhongdan Pan dan Gerald M. Kosicki (Eriyanto :2011)

\section{Struktur Sintaksis}

Struktur sintaksis dapat diamati dari skema berita. Sintaksis berhubungan dengan bagaimana seorang wartawan menyusun fakta dari sebuah peristiwa yang ada (headline, pernyataan, kutipan sumber, pengamatan atas peristiwa, opini, penutup) menjadi sebuah berita. Elemen sintaksis memberi petunjuk yang berguna tentang bagaimana seorang wartawan memaknai sebuah peristiwa dan hendak dibentuk bagaimana berita tersebut disajikan kepada audiensnya.

\section{Struktur Skrip}

Struktur skrip melihat bagaimana wartawan mampu mengemas suatu peristiwa menjadi berita. Laporan berita biasanya disusun sebagai suatu cerita yang alurnya harus mudah dipahami oleh audiens dan perlunya kelengkapan informasi berita sesuai fakta. Bentuk umum dari struktur skrip ini adalah 5W+1H (Who, What, When, Where, Why dan How). 


\section{Struktur Tematik}

Struktur tematik yaitu cara pandang wartawan atas suatu peristiwa yang dituangkan ke dalam berita dengan proposisi kalimat, hubungan antar kalimat, dan paragraf yang membuat teks berita secara keseluruhan. Perangkat framing dari struktur tematik adalah detail, koherensi, nominalisasi, bentuk kalimat dan kata ganti.

\section{Struktur Retoris}

Struktur retoris merupakan cara wartawan menekankan arti tertentu yang digambarkan dari pilihan gaya atau kata dari headline hingga body berita. Wartawan menggunakan perangkat retoris untuk membuat citra, meningkatkan penonjolan pada sisi tertentu dan meningkatkan gambaran yang diinginkan dari suatu berita. Terdapat beberapa elemen dalam struktur retoris diantaranya, leksikon, pemilihan kata metafora untuk menandai atau menggambarkan peristiwa. Selain melalui kata penekanan dapat dilakukan melalui grafis berupa gambar, tabel, dan foto.

\section{HASIL DAN PEMBAHASAN}

\section{Hasil analisis framing dari Sindonews.com}

Dari pemberitaan yang disajikan oleh Sindonews.com dan Detik.com, peneliti menganalisis dengan berpacu pada analisis framing milik Zhongdang Pan dan Gerald M. Kosicki. Daftar judul pemberitaan dari Sindonews.com yang akan di analisis :

\begin{tabular}{|l|l|l|l|}
\hline No & \multicolumn{1}{|c|}{ Judul Berita } & \multicolumn{1}{|c|}{ Penulis } & \multicolumn{1}{|c|}{ Waktu Dirilis } \\
\hline 1. & $\begin{array}{l}\text { Revisi UU Penyiaran Tak Halangi Kebebasan } \\
\text { Berekspresi }\end{array}$ & Sindonews & $\begin{array}{l}\text { Kamis, 27 Agustus } \\
2020-14: 40 \text { WIB }\end{array}$ \\
\hline 2. & $\begin{array}{l}\text { Uji Materi UU Penyiaran Diperlukan, Jangan } \\
\text { Karena Alasan Kebebasan Menjadi Liar }\end{array}$ & Puguh Hariyanto & $\begin{array}{l}\text { Kamis, 27 Agustus } \\
2020-15: 08 \text { WIB }\end{array}$ \\
\hline 3. & $\begin{array}{l}\text { PKS Dorong Revisi UU Penyiaran Kembali } \\
\text { Masuk Prolegnas Tahun Mendatang }\end{array}$ & $\begin{array}{l}\text { Rico Afrido } \\
\text { Simanjutak }\end{array}$ & $\begin{array}{l}\text { Jum'at, 28 Agustus } \\
2020-23: 06 \text { WIB }\end{array}$ \\
\hline 4. & $\begin{array}{l}\text { YouTuber Harus Bersyukur, KPI: Nasionalis, } \\
\text { RCTI \& iNEWS TV Lindungi Pelaku Industri } \\
\text { Kreatif }\end{array}$ & $\begin{array}{l}\text { Puguh Hariyanto } \\
\text { Sabtu, 29 Agustus } \\
2020-10: 57 \text { WIB }\end{array}$ \\
\hline 5. & $\begin{array}{l}\text { Berlebihan Jika Sebut UU Penyiaran Atur } \\
\text { Televisi Berbasis Internet Jadi Tak Demokratis }\end{array}$ & $\begin{array}{l}\text { Rico Afrido } \\
\text { Simanjuntak }\end{array}$ & $\begin{array}{l}\text { Senin, 31 Agustus } \\
2020-18: 39 \text { WIB }\end{array}$ \\
\hline 6. & $\begin{array}{l}\text { Dukung Uji Materi UU Penyiaran, Netizen: } \\
\text { Bukan Buat Batesin Kreativitas }\end{array}$ & Sindonews & $\begin{array}{l}\text { Senin, 14 September } \\
2020-09: 45 \text { WIB }\end{array}$ \\
\hline
\end{tabular}

Tabel 2. Judul Pemberitaan pada Sindonews.com 


\section{Sintaksis}

Headline pemberitaan yang disajikan pada periode 27 Agustus 2020 sampai 14 September 2020 memiliki kesan mendukung terhadap perevisian UU Penyiaran, selain itu headline yang disajikan juga memframing untuk mendorong pemerintah agar segera merevisi UU Penyiaran karena dianggap tidak adil bagi media konvensional dan juga jika merevisi UU Penyiaran tidak menghalangi kebebasan berekspresi bagi penggunanya. Adapun lead yang disajikan pada berita lebih menekankan pada merevisi UU Penyiaran diperlukan bahkan memiliki dampak positif dan tidak menghalangi kebebasan berekspresi seperti pernyataan yang beredar hal ini tercermin pada lead "Revisi Undang-Undang Penyiaran dinilai diperlukan mengingat penyiaran berbasis digital saat ini sangat masif" pada headline "Revisi UU Penyiaran Tak Halangi Kebebasan Berekspresi”.

Pada kesemua pemberitaan narasumber yang digunakan cukup beragam yakni dari Pakar Telematika Roy Suryo, Corporate Legal Director MNC Group Christoporus Taufik, Ketua Hubungan Media Badan Pengurus Pusat (BPP) Himpunan Pengusaha Muda Indonesia (HIPMI) Anthony Leong, Komisioner Komisi Penyiaran Indonesia (KPI) Pusat Yuliandre Darwis, Wakil Ketua Fraksi Partai Keadilan Sejahtera (PKS) hingga kalangan netizen hal ini cukup kredibel dan kompeten pada kasus ini. Namun dilihat dari narasumber yang dipilih ke semua narasumber tidak ada yang dari pihak partai yang pro terhadap pemerintah. Selain itu mereka (narasumber) kompak untuk menanggapi positif revisi UU Penyiaran yang mana hal ini terlihat jelas bahwa Sindonews.com memilih narasumber yang kredibel untuk menggiring opini masyarakat agar setuju dan mendukung perevisian UU Penyiaran.

\section{Skrip}

Pemberitaan yang disajikan oleh sindonews.com menonjolkan unsur apa dan mengapa. Apa yang terjadi yakni gugatan RCTI dan iNEWS TV untuk merevisi UU Penyiaran dan sebab mengapa UU Penyiaran tersebut harus direvisi. Seperti pada headline "Berlebihan Jika Sebut UU Penyiaran Atur Televisi Berbasis Internet Jadi Tak Demokratis" pada pemberitaan tersebut dijelaskan oleh narasumber yakni Roy Suryo seorang pakar telematika perlunya revisi UU Penyiaran lewat pernyataannya yang menyatakan "bahwa sebaiknya pemerintah dan DPR segera membuat UU Penyiaran baru yang sudah menyesuaikan dengan kondisi aktual terkini agar tidak ambigu dan multitafsir".

\section{Tematik}

Koherensi yang digunakan adalah koherensi sebab-akibat dan penjelas. Penggunaan koherensi sebab-akibat, dapat dilihat dari susunan kalimat pada headline "Berlebihan Jika Sebut UU Penyiaran Atur Televisi Berbasis Internet Jadi Tak Demokratis" yang mana dijelaskan pada salah satu pernyataan narasumber yakni "UU Penyiaran memang sudah seharusnya direvisi" narasumber juga memberikan penjelasan mengapa UU Penyiaran harus direvisi yakni agar dan tidak multitafsir, serta menyarankan pemerintah dan DPR untuk segera membuat UU Penyiaran baru yang sudah menyesuaikan dengan kondisi aktual terkini." 
Koherensi penjelas yang berarti kalimat yang ada dalam pemberitaan saling mempertegas dan memperjelas kalimat sebelumnya. Hal ini dapat pada headline pemberitaan "Revisi UU Penyiaran Tak Halangi Kebebasan Berekspresi" yang mana pernyataan narasumber yakni ketua BPP dan HIMPMI, Anthony Leong yang berpendapat bahwa merevisi UU Penyiaran tidak akan menghalangi kebebasan berekspresi di media sosial. Pada prinsipnya, konten digital perlu diatur (dalam UU Penyiaran-red), kata beliau juga menambahkan dengan menjelaskan kembali maksud pernyataannya yakni bahwa konten digital perlu ada mekanisme dan UU Penyiaran yang mengatur platform digital. Jangan sampai konten digital mempengaruhi dan membuat perilaku anak-anak menjadi buruk seperti konten SARA, kekerasan dan seks yang sangat gamblang di televisi platform digital.

Untuk pemilihan kata yang digunakan dalam kelima pemberitaan di atas membangun opini yang mendukung dan mendorong untuk segera merevisi UU Penyiaran, dibuktikan pada headline dan isi berita yang berjudul "YouTuber Harus Bersyukur, KPI: Nasionalis, RCTI \& iNEWS TV Lindungi Pelaku Industri Kreatif" dan juga "PKS Dorong Revisi UU Penyiaran Kembali Masuk Prolegnas Tahun Mendatang". Selain itu Sindonews.com juga memperhalus pemilihan kata dengan menggunakan kata "uji materi uu penyiaran", sedangkan portal berita lainnya menggunakan kalimat menggugat UU Penyiaran.

\section{Retrois}

Penggunaan kalimat 'revisi uu penyiaran', 'tidak menghalangi kreativitas', dan 'bebas berekspresi' hampir diulang dan ditekankan pada setiap berita yang diterbitkan oleh Sindonews.com. Hal ini dapat menunjukkan adanya penggunaan kata kiasan untuk memperhalus makna tuntutan dan kritik akan kasus tersebut. Selain itu dengan ini juga dapat menjadi salah satu penguat opini yang akan dibangun oleh Sindonews.com terhadap kasus ini, yakni bahwa revisi uu penyiaran tidak akan menghalangi kebebasan berekspresi dan kreativitas para pembuat konten digital (content creator). Sebelumnya beredar bahwa dengan direvisinya UU penyiaran akan dapat menghalangi demokratis dan kebebasan berekspresi masyarakat di luar sana.

Dengan penekanan kalimat yang disebutkan diatas yang telah digaungkan secara berulang seolah, Sindonews.com ingin mengklarifikasi pernyataan tersebut dengan membingkai opini bahwa revisi UU Penyiaran tidak akan membatasi kreativitas seseorang. Adapun pemilihan gambar pemberitaan, 2 dari 3 menggunakan ilustrasi dan sisanya menggunakan foto yang menjadi narasumber pemberitaan. Namun demikian pemilihan foto atau gambar pemberitaan yang dipilih oleh Sindonews.com cukup sesuai dan selaras dengan isi pemberitaan. 


\section{Hasil analisis framing dari Detik.com}

Daftar judul pemberitaan dari Detik.com yang akan di analisis :

\begin{tabular}{|l|l|l|l|}
\hline No & \multicolumn{1}{|c|}{ Judul Berita } & \multicolumn{1}{|c|}{ Penulis } & \multicolumn{1}{|c|}{ Waktu Dirilis } \\
\hline 1. & $\begin{array}{l}\text { UU Penyiaran Digugat, YouTuber Macan Idealis: } \\
\text { Jangan Batasi Kami }\end{array}$ & Eva Safitri & $\begin{array}{l}\text { Kamis, 27 Agu 2020 } \\
21: 03 \mathrm{WIB}\end{array}$ \\
\hline 2. & $\begin{array}{l}\text { Bantah Kebiri Medsos, RCTI Sebut Gugat UU } \\
\text { Penyiaran demi Moral Bangsa }\end{array}$ & $\begin{array}{l}\text { Tim } \\
\text { Detikcom } \\
14: 22 \mathrm{WIB}\end{array}$ \\
\hline 3. & $\begin{array}{l}\text { Kata Akademisi soal Gugatan RCTI yang Ingin } \\
\text { YouTube Tunduk UU Penyiaran }\end{array}$ & Andi Saputra & $\begin{array}{l}\text { Minggu, 30 Agu 2020 } \\
10: 54 \text { WIB }\end{array}$ \\
\hline 4. & $\begin{array}{l}\text { Muncul Petisi Tolak Gugatan RCTI yang Minta } \\
\text { YouTube dkk Tunduk UU Penyiaran }\end{array}$ & Andi Saputra & $\begin{array}{l}\text { Senin, 31 Agu 2020 } \\
12: 05 \text { WIB }\end{array}$ \\
\hline 5. & $\begin{array}{l}\text { DPR Minta MK Tolak JR RCTI Soal Konten YouTube } \\
\text { Harus Tunduk ke UU Penyiaran }\end{array}$ & $\begin{array}{l}\text { Tim } \\
\text { Detikcom } \\
14: 56 \text { WIB Sep 2020 }\end{array}$ \\
\hline
\end{tabular}

Tabel 3. Judul Pemberitaan pada Detik.com

\section{Sintaksis}

Headline pemberitaan yang disajikan pada periode 27 Agustus 2020 sampai 14 September 2020 pada portal media Detik.com memiliki kesan yang melemahkan adanya perevisian UU Penyiaran, Hal ini juga diperkuat dengan headline yang menggunakan kata kata sindiran seperti pada headline UU Penyiaran Digugat, YouTuber Macan Idealis: Jangan Batasi Kami dan Muncul Petisi Tolak Gugatan RCTI yang Minta YouTube dkk Tunduk UU Penyiaran. Adapun latar informasi yang disajikan pada berita detik.com lebih menekankan pada sindiran terhadap perevisian UU Penyiaran seperti pernyataan narasumber yang dipilih oleh Detik.com yang menanyakan apa motif di balik revisi UU Penyiaran, ia juga berspekulasi mungkin $R C T I$ itu merasa tersaingi oleh social media, atau apakah $R C T I$ punya social media juga yang mirip seperti YouTube yang belum bisa menyaingi YouTuber.

Pernyataan ini tercantum pada headline "UU Penyiaran Digugat, YouTuber Macan Idealis: Jangan Batasi Kami”. Pada kesemua pemberitaan narasumber yang digunakan cukup beragam dan dari berbagai kalangan baik pihak yang pro dan kontrayakni Politikus Vasco Ruseimy dan memiliki channel youtube, Direktur Jenderal Penyelenggaraan Pos dan Informatika (PPI) Kominfo Ahmad M Ramli, Corporate Legal Director MNC Group Christophorus Taufik, hingga Fakultas Hukum Universitas Esa Unggul Jakarta, Ahluddin Saiful Ahmad.

\section{Skrip}

Pemberitaan yang disajikan oleh Detik.com menonjolkan unsur siapa, apa dan bagaimana. Apa yang terjadi dan siapa yang menggugat yakni gugatan RCTI dan iNEWS TV 
untuk merevisi UU Penyiaran dan bagaimana dampak yang ditimbulkan jika UU Penyiaran tersebut direvisi. Seperti pada headline "Kata Akademisi soal Gugatan RCTI yang Ingin YouTube Tunduk UU Penyiaran" yang pada pemberitaan tersebut menjelaskan dampak buruk jika UU penyiaran tersebut direvisi. Narasumber bernama Ahluddin Saiful Ahmad, pengajar dari Fakultas Hukum Universitas Esa Unggul Jakarta menilai adanya permohonan Uji materiil Pasal 1 angka 2 Undang-Undang Nomor 32 Tahun 2002 tentang Penyiaran oleh RCTI dan iNEWS TV, bahwa penerapan pasal tersebut apabila langsung diterapkan dapat mengancam hak masyarakat mengenai kemerdekaan menyampaikan pendapat dan memperoleh informasi.

\section{Tematik}

Koherensi yang digunakan adalah koherensi sebab-akibat. Penggunaan koherensi sebab-akibat, dapat dilihat dari susunan kalimat pada headline "DPR Minta MK Tolak JR RCTI Soal Konten YouTube Harus Tunduk ke UU Penyiaran” yang mana dijelaskan pada salah satu pernyataan narasumber "pasal aquo yang berbeda terhadap pihak yang melakukan penyiaran dengan sarana pemancaran melalui media internet tidak relevan", memberikan sebab mengapa UU Penyiaran yang tidak diakomodir dapat menyebabkan ambiguitas dan ketidakpastian hukum dalam menyelenggarakan kegiatan penyiaran.

Selain itu narasumber juga memberikan sebab lain dari pernyataannya, yaitu siaran dalam UU Penyiaran merupakan kegiatan yang menggunakan pemancar spektrum radio yang telah ditetapkan pemerintah, sehingga OTT tidak termasuk dalam aturan UU Penyiaran. Dimana kalimat penjelas ini digunakan untuk menjelaskan gugatan yang diberikan oleh RCTI dan iNEWS TV tidak melenceng dari UUD 1945.

Adapun pemilihan kata yang digunakan dalam kelima pemberitaan di atas, Detik.com membangun opini yang bertentangan terhadap revisi UU Penyiaran dengan dibuktikan pada headline dan isi berita yang berjudul "UU Penyiaran Digugat, YouTuber Macan Idealis: Jangan Batasi Kami" dan "Bantah Kebiri Medsos, RCTI Sebut Gugat UU Penyiaran demi Moral Bangsa". Selain itu Detik.com menggunakan pemilihan kata yang lebih kasar dan bermaksud sindiran seperti pemilihan kata, "kebiri medsos", "macan idealis" yang memiliki makna kiasan. Berbeda dengan Sindonews.com yang memilih memperhalus menggunakan kata "uji materi", Detik.com menggunakan kata "Gugatan Penyiaran" yang dapat memberikan kesan negatif pada pihak penggugat.

\section{Retoris}

Penggunaan kalimat 'Gugatan UU Penyiaran' dan 'Gugatan RCTI dan iNEWS TV' terdapat semua pemberitaan Detik.com pada periode tersebut. Pengulangan kata "gugatan" pada pemberitaan di Detik.com menunjukkan penguatan konstruksi yang akan dibangun oleh Detik.com, yaitu ketidaksetujuannya atas gugatan yang dikeluarkan oleh RCTI dan iNEWS TV terhadap UU Penyiaran yang dapat membatasi konten-konten kreatif berbasis digital. Selain hal tersebut, pada judul berita "Bantah Kebiri Medsos, RCTI Sebut Gugat UU Penyiaran demi Moral Bangsa" terdapat penggunaan kata "kebiri" sebagai kata pengganti 
yang menunjukkan bahwa adanya gugatan ini, mengakibatkan kreatifitas para konten kreator pada platform Youtube seperti dibatasi.

Penggunaan majas metafora ini memberikan gambaran kasus yang diberitakan lebih memperkuat maksud dan konstruksi media Detik.com akan penolakan gugatan yang diajukan oleh RCTI dan iNEWS TV. Adapun penggunaan gambar atau foto pemberitaan yang dipilih oleh Detik.com cukup sesuai dengan isi pemberitaannya. Gambar yang dipilih yakni menonjolkan pihak penggugat (RCTI dan iNEWS TV) dan ilustrasi mengenai sosial media. Dari lima pemberitaan, dua diantaranya menggunakan gambar Gedung MNC sebagai gambar pemberitaan, dua lainnya menggunakan ilustrasi dan satu berita menggunakan foto narasumber.

\section{Refleksi perbedaan pembingkaian Sindonews.com dan Detik.com}

Merujuk pada pernyataan Sudibyo (dalam Sari, 2018) yang menyatakan bahwa setiap media massa dalam membuat pemberitaan mereka tidak sepenuhnya netral, melainkan mereka berpihak. Sama halnya dengan pemberitaan yang dimuat pada Sindonews.com dan Detik.com. Keberpihakan media massa dipengaruhi oleh kepentingan dan tujuan media massa itu sendiri. Selain keberpihakan, media massa dalam membuat pemberitaan tidak lepas dari pembentukan konstruksi realitas. Peter L Berger dan Thomas Luckman menjelaskan mengenai tahapan media massa dalam mengkonstruksi realitas sosial, yaitu objektivasi, internalisasi, dan eksternalisasi.

Tahapan konstruksi media dilakukan oleh wartawan terhadap objek pemberitaan yang sesuai dengan sudut pandang media massa. Dalam menuliskan sebuah peristiwa, media memiliki strategi wacana tersendiri. Fakta yang wartawan ambil didasari oleh penentuan sudut pandang dan gambaran yang diyakini oleh wartawan. Oleh sebab itu, wartawan dapat menuliskan pemberitaan sesuai dengan pandangannya terhadap suatu peristiwa pada portal berita.

Berdasarkan hasil analisis menggunakan metode framing Zhongdan Pan dan Kosicki yang membangun konstruksi realitas serta pembingkaian sebuah berita yang dibagi menjadi 4 struktur besar yakni sintaksis, skrip, tematik dan retoris. Pada kasus gugatan yang diajukan oleh RCTI dan iNEWS TV terhadap UU Penyiaran terdapat perbedaan yang signifikan pada kedua media dalam menyajikan pemberitaan tersebut. Sindonews.com mengkonstruksi realitas yang dihubungkan dengan rutinitas dan konvensi berita yang memperkuat dukungan terhadap gugatan yang diajukan oleh RCTI dan iNEWS TV terhadap UU Penyiaran.

Hal ini juga dapat disebabkan oleh faktor keberpihakan dan kepemilikan media yang memang masih dalam satu lingkup perusahaan. Adapun jika dilihat dari headline, pemilihan kata dan pemilihan narasumber yang mereka pilih seolah membangun kesan yang positif terhadap kasus tersebut. Selain itu pemberitaan yang dimuat oleh Sindonews.com juga memiliki maksud lain yakni sebagai bentuk klarifikasi perusahaan terhadap rumor yang beredar terkait dampak negatif jika gugatan UU Penyiaran dikabulkan.

Sebaliknya Detik.com mengkonstruksi realitas yang dihubungkan dengan rutinitas dan konvensi berita menghasilkan pemberitaan yang melemahkan kasus gugatan RCTI dan 
iNEWS TV terhadap UU Penyiaran. Pemberitaan yang dimuat oleh Detik.com dilihat dari headline, pemilihan kata dan narasumber menunjukan kesan tidak adanya desakan kepentingan yang harus membuat UU Penyiaran segera direvisi. Meskipun demikian Detik.com tidak memojokkan media penggugat melainkan Detik.com menekankan pada dampak negatif yang timbul jika gugatan tersebut dikabulkan.

\section{SIMPULAN}

Berdasarkan hasil analisis pembingkaian berita yang telah dilakukan dan dipaparkan pada pembahasan sebelumnya terhadap Sindonews.com dan Detik.com pada kasus Gugatan UU Penyiaran RCTI dan iNEWS TV menyebutkan perbedaan pembingkaian dari kedua media tersebut yang akan dijelaskan sebagai berikut:

1. Framing pemberitaan yang dilakukan oleh Sindonews.com, terkait berita Gugatan UU Penyiaran RCTI dan iNEWS TV melalui analisis framing Zhongdang Pan dan Kosicki sangat dipengaruhi oleh pemilik media tersebut. Pemberitaan yang dibingkai oleh Sindonews.com memberikan dukungan terhadap kasus ini dan mendorong untuk segera dilakukannya revisi UU penyiran. Sindonews.com juga menggiring opini masyarakat dengan membangun kesan positif dari rumor yang beredar di masyarakat terhadap perevisian UU Penyiaran yakni revisi UU Penyiaran perlu dan tidak membatasi kebebasan dan kreativitas konten kreator. Framing Sindonews.com tidak lain dipengaruhi oleh kepemilikan media, mereka masih tergolong dalam satu payung perusahaan yang sama yakni di bawah MNC Group. Hal tersebut didukung oleh penggunaan narasumber, pemilihan kata yang lebih halus, lead, headline beserta gambar pemberitaan yang dipilih oleh Sindonews.com dalam memberitakan kasus ini.

2. Berbeda dengan Sindonews.com, Detik.com memberikan framing pemberitaan yang melemahkan dukungan pada Gugatan RCTI dan iNEWS TV terhadap revisi UU penyiaran serta tidak menstimuasi adanya urgensi untuk merevisi UU penyiaran ini. Pemberitaan yang dibingkai oleh Detik.com sedikit banyak dipengaruhi oleh agenda media, ini berhubungan dengan Detik.com yang merupakan pemain lama portal berita online selain itu Detik.com juga menjadi portal berita online yang sukses dan diakses masyarakat adapun jika UU Penyiaran tersebut direvisi maka sedikit banyak akan berpengaruh pada kebijakan portal berita online termasuk Detik.com. Hal tersebut didukung oleh pemilihan kata, lead, headline, serta gambar pemberitaan yang menonjolkan pihak penggugat.

\section{Buku Fisik}

\section{DAFTAR PUSTAKA}

Bungin, B. (2010). Metodologi Penelitian Kuantitatif: Komunikasi, Ekonomi, dan Kebijakan Publik dan serta Ilmu-ilmu Sosial Lainnya. Edisi ke-2. Kencana Prenada Media Grup. Jakarta.

\section{Buku Online}

Bungin, B. (2011). Konstruksi Sosial Media Massa. Jakarta: Kencana.

Eriyanto. (2011). Analisis Framing : Konstruksi, Ideologi, dan Politik Media. LKIS.

Romli, A. S. M. (2012). Jurnalistik Online: Panduan Mengelola Media Online. Nuansa Cendekia. 
e-PDF

Handoko, N. W., Emeraldien, F. Z., \& Purnomo, A. 2020. Analisis Framing Terhadap Pemberitaan Klub Sepak Bola Persebaya. Jurnal Penjakora, 6(2), 82-91.

Khoirulla, A. K., Abiyu, S., Raihan, S. A. T., \& Febrianita, R. (2021). Membingkai Risma di Portal Berita Online: Jejak Penanganan Covid-19 di Surabaya. Tuturlogi: Journal of Southeast Asian Communication, 2(1), 53-62.

Leonarda Johannes R.S. (2013). Analisis Framing Pemberitaan Konflik Partai Nasional Demokrat (Nasdem) Di Harian Media Indonesia Dan Koran Sindo. E-Komunikasi, $01,10$.

Sari, I. P. (2018). Keberpihakan Media Dalam Pemilihan Presiden 2014. Jurnal Penelitian Komunikasi, Vol. 21 No, 73-86.

Artikel Berita Online

Adam, Aulia. (2018). 8 Konglomerat Media di Indonesia via Jalur Media TV \& Cetak. Available in: https://tirto.id/8-konglomerat-media-di-indonesia-via-jalur-media-tvcetak-cEv7

Apridawaty,Titi Sutinah. (2020). Podcast dengan RCTI, Deddy Corbuzier: Content Creator Dilindungi, Tanggung Jawab di OTT. Available in:https://lifestyle.sindonews.com/read/148840/158/podcast-dengan-rcti-deddycorbuzier-content-creator-dilindungi-tanggung-jawab-di-ott-1598792903

Hariyanto,Puguh. (2020). Uji Materi UU Penyiaran Diperlukan, Jangan Karena Alasan Kebebasan Menjadi Liar. Available in:https://nasional.sindonews.com/read/145830/13/uji-materi-uu-penyiarandiperlukan-jangan-karena-alasan-kebebasan-menjadi-liar-1598515737

Hariyanto, Puguh. (2020). YouTuber Harus Bersyukur, KPI: Nasionalis, RCTI \&iNEWS TV Lindungi Pelaku Industri Kreatif. Available in:https://nasional.sindonews.com/read/147838/13/youtuber-harus-bersyukur-kpinasionalis-rcti-iNEWS TV-lindungi-pelaku-industri-kreatif-1598670534

Medistiara, Yulida. (2020). Gugat UU Penyiaran, RCTI akan Hadirkan 3 Ahli di MK. Available in:https://news.detik.com/berita/d-5172713/gugat-uu-penyiaran-rcti-akanhadirkan-3-ahli-di-mk? ga=2.101741377.1173027610.1600953529$\underline{445654949.1538091000}$

Novianto,Raka Dwi. (2020). Uji Materi UU Penyiaran, MK Minta DPR Jelaskan Makna 'Media Lainnya'. Available in:https://nasional.sindonews.com/read/163896/13/ujimateri-uu-penyiaran-mk-minta-dpr-jelaskan-makna-media-lainnya-1600067373

Pertiwi, Wahyunanda Kusuma. (2020). Duduk Perkara Gugatan RCTI yang Ancam Kebebasan Siaran Live di Medsos. Available in:https://tekno.kompas.com/read/2020/08/28/14045847/duduk-perkara-gugatanrcti-yang-ancam-kebebasan-siaran-live-di-medsos?page=all

Ramdhani, Jabbar. (2020). Punya Channel YouTube, Roy Suryo Tetap Setuju UU Penyiaran Digugat. Available in: https://news.detik.com/berita/d-5149652/punya-channelyoutube-roy-suryo-tetap-setuju-uu-penyiarandigugat? ga=2.97074143.1173027610.1600953529-445654949.1538091000

Safitri, Eva. (2020). UU Penyiaran Digugat, YouTuber Macan Idealis: Jangan Batasi Kami. Available 
E.ISSN:2334-4606, P-ISSN:2087-2461 http://jurnal.unissula.ac.id/index.php/makna DOI:http://dx.doi.org/10.30659/jikm.9.2.73-87

youtuber-macan-idealis-jangan-batasi-

kami? ga=2.22626171.1173027610.1600953529-445654949.1538091000

Saputra, Andi. (2020) Ahli Hukum Keberatan Gugatan RCTI yang Ingin YouTube Tunduk ke UU Penyiaran. Available in:https://news.detik.com/berita/d-5150381/ahli-hukumkeberatan-gugatan-rcti-yang-ingin-youtube-tunduk-ke-uupenyiaran? ga=2.100876225.1173027610.1600953529-445654949.1538091000

Saputra, Andi. (2020). Kata Akademisi soal Gugatan RCTI yang Ingin YouTube Tunduk UU Penyiaran. Available in:https://news.detik.com/berita/d-5152389/kata-akademisisoal-gugatan-rcti-yang-ingin-youtube-tunduk-uupenyiaran?.ga=2.93558749.1173027610.1600953529-445654949.1538091000

Saputra, Andi . (2020). Muncul Petisi Tolak Gugatan RCTI yang Minta YouTube dkk Tunduk UU Penyiaran. Available in:https://news.detik.com/berita/d-5153373/muncul-petisitolak-gugatan-rcti-yang-minta-youtube-dkk-tunduk-uupenyiaran?.ga=2.265314127.1173027610.1600953529-445654949.1538091000

Sindonews. (2020). Dukung Uji Materi UU Penyiaran, Netizen: Bukan Buat Batesin Kreativitas. Available in:https://nasional.sindonews.com/read/163610/13/dukung-ujimateri-uu-penyiaran-netizen-bukan-buat-batesin-kreativitas-1600049389

Sindonews. (2020). Revisi UU Penyiaran Tak Halangi Kebebasan Berekspresi. Available in :https://nasional.sindonews.com/read/145790/13/revisi-uu-penyiaran-tak-halangikebebasan-berekspresi-1598512086

Sindonews. (2020). Uji Materi UU Penyiaran untuk Kesetaraan dan Tanggung Jawab Moral Bangsa. Available in:https://nasional.sindonews.com/read/146420/13/uji-materi-uupenyiaran-untuk-kesetaraan-dan-tanggung-jawab-moral-bangsa- 1598544517

Simanjuntak,RicoAfrido. (2020).Berlebihan Jika Sebut UU Penyiaran Atur Televisi Berbasis Internet Jadi Tak Demokratis. Available in: https://nasional.sindonews.com/read/149812/13/berlebihan-jika-sebut-uu-penyiaranatur-televisi-berbasis-internet-jadi-tak-demokratis-1598872125

Simanjuntak,Rico Afrido. (2020). PKS Dorong Revisi UU Penyiaran Kembali Masuk Prolegnas Tahun Mendatang. Available in:https://nasional.sindonews.com/read/147538/12/pks-dorong-revisi-uu-penyiarankembali-masuk-prolegnas-tahun-mendatang-1598630923

Tim detikcom. (2020). Bantah Kebiri Medsos, RCTI Sebut Gugat UU Penyiaran demi Moral Bangsa Available in:https://news.detik.com/berita/d-5150324/bantah-kebirimedsos-rcti-sebut-gugat-uu-penyiaran-demi-moralbangsa?.ga=2.21247227.1173027610.1600953529-445654949.1538091000

Tim Detikcom. (2020). DPR Minta MK Tolak JR RCTI Soal Konten YouTube Harus Tunduk ke UU Penyiaran. Available in:https://news.detik.com/berita/d-5172483/dpr-mintamk-tolak-jr-rcti-soal-konten-youtube-harus-tunduk-ke-uupenyiaran?.ga=2.67386577.1173027610.1600953529-445654949.1538091000

Utama, Felldy. (2020). UU Penyiaran, KPI Dorong Pengaturan Media Baru dalam Konteks Kesetaraan. Available in:https://nasional.sindonews.com/read/148492/12/uupenyiaran-kpi-dorong-pengaturan-media-baru-dalam-konteks-kesetaraan1598760504 